Arab World English Journal (AWEJ) Volume 12. Number3 September 2021

DOI: https://dx.doi.org/10.24093/awej/vol12no3.13

Pp. 186-200

\title{
"Bloometizing" the EFL Literature Classroom through a Dialogic Model: A Barometer for Academic Change
}

Amina Bouali

Department of English, Faculty of Foreign Languages

Oran 2 University, Oran, Algeria

Email: amy.bouali@gmail.com

Received: 3/3/2021 Accepted: 9/3/2021 Published: 9/24/2021

\section{Abstract}

On the 21 st century scent of educational development, 'dialogism' hogs the limelight of leading academics, mapping ergo a stiff stronghold for active learning pedagogies. Regarding the field of literature more sensibly considered in English as Foreign Language (EFL) context, the plea for embracing interactive talks reverberates discernably in the air, yet, engaging practices are still an overlooked real-world praxis. Given this reality, the current paper endeavours to endorse the implementation of a new dialogic model that extrapolates its foundation-stone techniques from both of Bakhtin's (1983) discursive dialogues and Socratic argumentations. The pertinent problematics in this study is to investigate the effect of this model on enhancing learners' higherorder critical thinking skills (HOTSs). To fulfil this target, the researcher has embarked on an Experimental Study based on a pre/post-testing, carried on painstakingly with second-year EFL students at Oran2 University, Algeria. Substantially, after appraising the treatment results through SPSS, the study reveals that adopting such a dialogic model is a robust sinew for "Bloometizing" EFL literature classroom, namely by stimulating and revitalizing the learners' cognitive reasoning potentials at a very high complexity. Besides, in-class interactions help the students build empathy with literary texts and strengthen their analytical strategies. From this vantage point, the paper, finally, hopes that teachers adopt this dialogic model as a fitting instructional capstone to bringing literature back to life before the learners' eyes and to add the 'wow' factor inside literature classrooms.

Keywords: Bakhtin's discursive dialogues, dialogism, HOTSs, EFL literature classroom, Socratic argumentations

Cite as: Bouali, A. (2021). "Bloometizing" the EFL Literature Classroom through a Dialogic Model: A Barometer for Academic Change. Arab World English Journal, 12 (3) 186-200.

DOI: https://dx.doi.org/10.24093/awej/vol12no3.13 


\section{Introduction}

In an unpreceded epoch of globalization and a race against the clock development interfering with the very minutiae of individualists' hectic life and multifarious spheres of influence, not least education, the academy is in transition to democracy. Correspondingly, many transmissive modes of teaching have started gradually to lose their academic rigour underpinning plenty of room for liberal active learning. Beginning at the outset of the $21^{\text {st }}$ century, interests in active teaching stem rather abruptly offering a robust boost for restoring education to the former glorious theory of dialogism, pioneered in the most inspiring studies of Vygotsky (1962), Freire (1985), and Bakhtin (1983). In their complementary prevailing assumptions, those prominent researchers - renowned for considerable stature and longstanding career in the field of dialogism - have conveyed a distinguishingly evidenced reality that language is, overall, a socio-ideological (Bakhtin) or socio-cultural phenomenon (Vygotsky). It is held from their version of thoughts that language is a constructive process created through the reciprocate transmission of beliefs, ideas, and values exchanged between two or more speakers in a given speech community. The strongest claims in this line consider the semantics of words as a matter of societal consensus stemming chiefly from respect, equality, and involvement shared between homogeneous culture(s) (Renshaw, 2004). From a pro side, Bakhtin's resonating theory may be credited with extraordinary quantities of wisdom and personal visualisation exerting a positive influence on modern pedagogy. One of his vital contributions to teaching is that many monologic, uni-volcanist and passive habits of learning are currently eschewed in favour of teaching dynamism and students-centredness. This implies that fostering dialogues inside classes is, in the 21 st century, eulogised as the boon rather than the bane for today's mainstream education. For instance, classroom talks are recently defined as a sinew strategy that is likely helpful in enhancing advanced language proficiency, and stimulating meta-level reflections at higher-level complexity (Murphy, Wilkinson, Soter, Hennessey, \& Alexander, 2009; Reznitskaya et al., 2009).

However, when lifting the eyes to this momentous method of study pertinent to L2 teaching, it becomes visible that Bakhtin's Dialogism has stepped up from shadow into luminosity. Nevertheless, this beam of light could only brighten a diminutive deal of space in the world of didactics today. This is to say, as the literature suggests, a dialogic model of teaching is recommended as a state-of-the-art framework. It facilitates the operational flow of open, spontaneous, and in-depth exchange of thoughts in such an efficient way that can in and of itself spur multi-dynamic cognitive abilities and help to strengthen the students' empathy with the literary texts; intellectually (Seymour, Thanos, Newell, \& Bloome, 2020) and emotionally (Weigand, 2004). Nonetheless, albeit the full-scale plea for embracing dialogism as an effective teaching alternative at schools, obsolete protocols are still grinding on very actively at work (Reznitskaya, 2012). In other words, by virtue of outdated teaching mindsets (reluctancy for a change), some teachers are still refusing to get dragged from their puritanical ivory towers to come down-to-earth where practical and involving strategies are compellingly inevitable, thereby, a teacher-students crack appears persistently jeopardising and critical (Wolfe \& Alexander, 2009).

From another gloomy corner, the previously established research divulges diffracted spectra of attitudes regarding how to apply dialogic practices inside the classroom, culminating into three teaching paradigms: (1) dialogue as a "scaffolding" instruction, where contingency and 
reflectiveness of interaction take place between two participants; one is the guide, and the other one accomplishes the same challenging assignment. (2) Dialogue as a conversation: talks are undertaken in a community learning milieu where questions are directed to help the learners share their knowledge, taste and opinions in such a vital way that aims to restore harmony and consensus. 3/ Dialogue as an inquiry: interaction is a kind of collective debate and conflict that arise through an individually posed question, then debates set in small groups to search for a solution. Finally, the students work collaboratively to discuss and report the findings (Renshaw, 2004). Practically speaking, none of those previous studies taps into different dialogic teaching forms to foreground an integrative dialogic model leaving a chasm in pedagogy. Painstakingly, it is somehow between the Scylla of practical hangover and the Charybdis of deficiency where this study shapes the niche. Its chief objective is to resurrect Dialogism as a core teaching framework inside EFL literature classes, incorporating some professional development activities that create a borderland between Bakhtin's power of discursive talks and the Socratic unique philosophy of argumentation. The idea is to gauge whether this template model can transform into a powerful medium of instruction to teaching literature that may help reconfigure the learners' habits of mind. To reach these ends, the empirical study carried out along the lines of this paper targets to answer the following research questions:

1. What is the effect of teaching literature through a dialogic teaching model on EFL students' critical thinking skills?

2. Does in-class debates and conflicts help to deepen students' understanding and interaction with the literary texts critically?

However, before delving into this research paper's empirical study, it is enormously crucial to capture a bird's eye view on the main definitions of the term 'dialogism' and its possible applications in EFL literature classrooms.

\section{Dialogism and Second Language Teaching}

In its broadest sense, dialogism is a fashionable ideal in the world of didactics today, which advocates collaboration and reflexive interaction between all the learners in the class. Interestingly, this new trend in language teaching has been settled on by extrapolation from tempestuous studies conducted on the social perception of the language; lately termed Dialogicality (Dialogism). It has inadvertently given an enormous build-up of language and literature learning in some years since.

In light of the recent interest in dialogism among L2 scholars, explorers on the field locate the genesis of the theory in Russian philologist Bakhti's coining of the term dialogicality (Koschmann, 2015). Bakhtin's notion of dialogism aims fundamentally to showcase the sociocognitive function of the language and its paramountcy over human customary conversations and cognition (Kozulin, 1996). Stricto sensu, the bedrock of dialogism, partaking roughly in the enormously influential ideas of Bakhtin, is one that dialogue is a genuine demonstration of reality and the living prism of common sense. It is only "born between people collectively searching for truth, in the process of their dialogic interaction" (Bakhtin, 1984, p. 110). Ideas as such foreground admittedly a liaison between language studies and literature. As related to the study of narrative discourses, a parade of universally fictional novels seem to employ a multivoiced fiction technique that reinforces the systematic social network between spatial and 
temporal discourses. Dialogism, ergo, serves as the vein that resonates with aesthetic wisdom. It frequently helps to capture scrupulously the intermeshing links between texts, and therefore, grappling the polyphonous voices reverberating within and across specific utterances (Koschmann, 2015).

Irrefutably, Bakhtin's dialogism has issued the cardinal framework of thoughts that becomes engendered not only in sociolinguists and literary scholars' casts of mind but also among academics. Importantly, sparked interest in dialogism has been first divulged by the Brazilian Marxist educator Paulo Freire, an ardent disciple of liberal teaching values against dictatorial education. In his illustrious seminal work of reference Pedagogy of the Oppressed (1970), Freire released the imperialistic ideology of 'Banking' utilized metaphorically to personify the students as investment 'banks'. Banking thus is a newly minted philosophy to learning that symbolises "learners' receiving knowledge passively as empty vessels from the teacher, who is supposed to be store-house of knowledge, in the traditional teacher-centred classroom" (Alam, 2013, p. 27). Pitifully then, the passivity prevalent in this strategy may cause mental and physical paralysis in the students. As for Freire himself, banking is an imperialistic ideology inflicted cruelly on the learners, who are compelled to digest the thoughts of the teacher blindly forbearing a parrot-fashion (Friere, 2000).

Leading rebellion against those flagrantly dormant teaching styles, Freire \& Shor (1987) have eloquently maintained the right of academic emancipation and the need to foster discussion-based strategies as a means of establishing a check-and-balance relation between the teacher and the learners inside classes. Led by this creed, they both define dialogue as

A moment where humans meet to reflect on their reality as they make and remake it [...] dialogue seals the relationship between the cognitive subjects, those who know, and who try to know ... dialogue is the sealing together of the teacher and the students in the joint act of knowing and re-knowing the object of study. (pp. 98-100)

By way of inference, dialogues are deemed a contemplative remapping of reality, based mostly on vital personal experiences. However, to summon up the learners to participate, teachers are pled to animate their classrooms through rigorous and lively talks, which sustain the students to discover the materials and themes of learning by themselves in a mutually dynamic fashion.

By and by, Freire's pedagogy of liberation and hope could quite promptly instil curiosity in contemporary applied linguists, who inaugurate sedulous attempts to depict the term "dialogism," as a good point of reference per se. For instance, Reznitskaya and Gregory (2013) define dialogic teaching as "a pedagogical approach that involves students in the collaborative construction of meaning and is characterised by shared control over the key aspects of classroom discourse" (p. 114). Besides, other scholars find in-class debates a constructive teaching methodology that involves learners of multiple learning styles and competence to participate in a collective milieu, reaching thus a fitting capstone of self-discovery and heuristic thinking (Alexander, 2020; Fenner, 2001; Skidmore \& Murakami, 2016). Analogously, dialogism embodies the drawing power for urging the learners to collaborate through harmonious, dynamic and productive discussions, which are apt to help them stimulate their communicative language competence and critical thinking (Littleton \& Howe, 2010), problem-solving skills, and inculcate a spirit of responsibility and leadership (Littleton \& Mercer, 2013; Lyle, 2008). Therefore, it is 
fair to say that a significant body of ground-breaking ideologies invested in dialogism has not just put flesh on the bare bones of the modern classroom, but it has also brought conspicuously the term 'dialogue' blazoned across the strip of ESL.

\section{Dialogism and Literature Classroom}

Dialogism and literature are intermeshing streams in themselves, for most literary texts are peculiarly dynamic semiotic products, which are only permeated throughout a deep personal commitment and self stylistic judgements. Unboundedly, as springing full-blown from Bakhtin's mind, the text is not to take as truly self-sufficient narrative, but as a mosaic spectrum of borrowed literary voices, undercurrents, and nourishing thoughts without which rhetorical power slackens off. It is interilluminating meeting space between distantly subtle brains communicating from else space and era. As described by Bakhtin (2014), "every novel is a dialogized system made up of the images of "languages," styles and consciousnesses that are concrete and inseparable from language" (p. 247). In this account, the living mixture of colourful voices of skirmishing and concord on the borders suggest that the only way to penetrate a discourse is to pore over its context through the eyes of someone else's language building system (Bakhtin, 2014). This is to allude to the fact that dissolving of the intricate threads of meaning across literature, time and space, does not imply only socio-cultural imperialistic scrutiny of literariness but also invites the readers to discuss the deeply-entrenched voices of the mind to listen with tact and thoughtfulness to their articulated words as to their sighs and silences (Schultz, 2001). So, dialogues are regarded as a food-for-thought mechanism, an open variegated venue for stimulating discussions and in-class debates, capitalizing upon socio-cultural and aesthetic responses to the texts (Delanoy, 2005).

In literature education parlance, emphasis on 'dialogism' plays a crucial role above all other teaching practices, for this latter grants a high valuation on the critical scrutiny of literary texts. As a vigorous source of inspiration, dialogic teaching has underpinned a stiff buttress to Rosenblatt's Reader-Response Theory $(1938,1978)$; a commonly stimulating strategy in the late 1960s that immensely impresses inspiring ideas on how to respond to arts. To Rosenblatt's thesis, any literary text is a lacklustre, lifeless, and senseless organic frame, before the reader who shows up to endow life to text by actively constructing entailments and value judgements. Therefore, interpretive empathy enables the replenishment of meaning. Given the meta-textual power of the narratives, it is highly recommended that the implementation of dialogues in various pedagogical contexts deepens the understanding of the literary work in so many ways, in the sense that the reader draws on both his nostalgic experiences and those emotions he lives out along the reading process, there where meaning flows out of both banks, the purely personal reactions and inherited or culturally conditioned ways of reading (Larson, 2009).

On the other end of the spectrum, some theoreticians advocate the view that the integration of students-students interactions during the analysis of literary works is a robust booster to English language development. They have prolific fruitful impacts on how adults install their intrinsic communicative language faculties in ingeniously occurring conversations, and how they arrange words in written compositions using a high-level style (Wells, 2009). In the same vein, Ferguson and Young (1996) highlight the importance of patterned dialogues and improvisation inside literature classes in enhancing the narrative genre of collaboration and reinforcing the internalisation of English language infrastructure. With the same favourable note, 
the value of discussions is also celebrated for its capability to emphasise ethical and ethnical forms of speculation upon the texts that can be very beneficial for promoting more openmindedness and tolerant breadth of vision to other's cultures (Morgan \& Cain, 2000). Succinctly, dialogism in literature classrooms is often considered a barometer for bona fide social and academic change. It allows a nudge in the right direction towards a free learning spirit, which would have never been so autonomous through passive teaching means (Skidmore \& Murakami, 2016).

Practically speaking, multivariate trajectories of conjectures seem to correlate regarding how to apply dialogism effectively inside classes, literary or otherwise. These shifting sands in researchers' perspectives had either abide by Bakhtin's symphonic dialogues, or Socratic argumentative pedagogy, which are often conceived of as an antithetical strategy to each other (Renshaw, 20). The first method is extrapolated from a socio-cultural model of instruction, which aims to cultivate a sense of harmony, collaboration and communication between the students inside the classroom. It is a community language teaching strategy, which permeates the learners to work in two or more group discussions within which communication circulates throughout an interactive "peace-making" system. Noteworthy, this genre of dialogism encourages interactional practices that are more explanatory than exploratory, and are mostly base on the study of language that has a primary community-building role in the process of learning. Through this fashion, the learners ventriloquise other teachers, texts, or learners' accents, values and beliefs to build their own interventions and entailment of concepts. Therefore, the reception of knowledge is inferred passively from varied language resources, either a pearl of stored wisdom or other participants' illumination in the class.

Dissimilarly, Socratic Questioning or inquiry-based conflicts is a kind of digging-deeper activity, which embodies "Socrates' belief in the power of asking questions, prize inquiry over information and discussion over debate" (Delic \& Becirovic, 2016, p. 514). It is a method that invests in the potential of collisions and debates (Hermeneutics) in enriching the visualisation of literature and culture, and also in sharpening the students' critical and cognitive thinking skills. In this flash of enlightenment, thinking looks like in philosophy, it is fuelled by the uncanny power of questioning and not by the rightness of answering what the learners would strive to find or create. As delineated by Elder and Paul (1998), "questions define tasks, express problems and delineate issues", whereas answers "signal a full stop in thought" (p. 297). More importantly, this strategy is often underlined by the following characteristics: 1/ Thinking is prioritised over conversing and new inquiries over deep-dyed perspectives, 2/ Students are provoked to enquire and to reason by themselves, rather than depending on grounded authority or accepted opinions for their knowledge, 3/ Active construction of facts and the application of reasoned argumentation to explore centrifugal cultural and parodic rhetorical ends, 4/ Learners work away from that original intentions, struggling against boundaries and conventions, 5/ the teacher plays the role of a 'gadfly' for his students. He teases them with brainteasing questions to help them construct meaning by themselves that collides mostly with others' perspectives.

\section{Dialogism, Critical Thinking, and Literature Classroom}

In academic parlance, critical thinking is a catchy term that means for McPeck (1981) "the propensity and skill to engage in an activity with reflective scepticism" (p. 8). It also signifies self-oriented, self-dependent, and self-monitored reasoning, which necessitates 
fastidious levels of excellence and thoughtful command of their utilisation (Paul \& Elder, 2003). Dialogues and critical thinking have consensually been intermeshing in themselves, in the sublime conviction that the exploration of literature nurtures students' subtlely sophisticated activities of mind; what Bloom refers to as (HOTSs). Indebtedly, Bloom is credited for developing the primary common cognitive skills in learning in his widely referenced book Taxonomy of Educational Objectives. His stratification of HOTSs captures the aptitude to think critically in two levels: lower-order level, overlapping knowledge (the retention of specific facts), and comprehension (the ability to understand the meaning of these facts), and a higherlevel that straddles application (involves students to use knowledge, skills, or techniques in new contexts), analysis (ability to draw a distinction between fact and opinion and raise questions to get information that answers or solves problems), synthesis (generate novel ideas and to seek alternative orientation of life), and evaluation (deliberate upon certain aspects of life, and appraise their value in a new context). HOTSs, as Bloom advocates, are ideally paramount pace to ensure the active learners' engagement in the complexities of literary analysis and criticism (“Bloom's Taxonomy of Educational Objectives”, n.d.).

Advocating the interplay between education, literature and critical thinking, further studies have drawn upon the clout of the negotiation of textual meanings in forging a futile seedbed for intensive and illuminative critical readings (Morgan \& Cain, 2000), synthetic thinking, and augmented reflective thinking potentialities (Hayes, 1990; Strickland, Dillon, Funkhouser, Glick, \& Rogers, 1989). As construed by Langer (1995), the very idea of goading on the students to map their own envisionment out of the texts will permeate them "to explore new horizons, and consequently, enter the realm of "literary thinking" (p. 57). Apropos of the applied models related to dialogism, researchers have made some experiments to show the effect of literary-directed dialogues on learners' critical thinking. For instance, Hayes (1990) confers that using Bakhtin's dialogic model should build on eight phases, which support the learners to reflect on reading on their own by sharing, judging, and comparing their arguments to those of others. This strategy will allow the students to deepen their evolving meaning of both literature and critical thinking. In the same vein, Commeyras (1993) considers the employment of instructional conversations yoked with discussion webs an effective strategy to promote students' HOTSs, which in turn, help them discover what is behind the scenes of passages; interpreting, illustrating, and founding aesthetic judgements on multifarious aspects and issues related to themes, characterisation, tone, and so on.

On the other hand, some scholars like Seymour et al. have sketched a prescriptive teaching method based on the pedestal of Socratic Dialogic Literary Argumentation. To their mind, argumentative conversations is a "bounce off" — "arguing-to-learn" - tactic of learning in literacy classes. Its value resides in its potency to bring learners from the entire corners of the class talking and debating collaboratively in a way that helps them come to terms with each other's deviant viewpoints, to penetrate the membrane covering the literary cortex profoundly, and to better reconcile with themselves and the world surrounding (Seymour et al., 2020). Admittedly, the idea of tracing the most recent stamps of advancements in this area of concern is to appraise the degree of the pedagogical progress achieved, draw links, and then expose the gap. What is transparently neglected in the area of literature teaching vis-a-vis dialogism is the role of conversations and conflicts together to add rigour in the analysis of literature, and enhance learners' HOTSs. To imbue this chasm, the researcher will endorse a dialogic model that taps 
into Bakhtin and Socratic paradoxical theoretical resources by putting them constructively downto-earth. The fulcrum of the whole study is to examine the effect of inquiry dialogues on learners' HOTSs and what quintessentially animating debates can contribute to the diagnosis of the literary discourses in general.

\section{Research Methodology \\ Design}

The experimenter has partaken in a true experimental design by anchoring in cause-andeffect treatment and random assignment. In this process, the participants have set randomly in two tests (pre and posttest), and then their grades had been assessed before and after an intervention of change had been manipulated.

\section{Participants}

Participants that act as guinea pigs for the current research are 32 students studying in the English department at Mohamed Ben Ahmed, Oran2 University (Algeria). Those participants had been the experimenter's students in Literary studies courses all over the academic year 20182019. Most of them reveal a great deal of persistence and willingness to take part in this experimental experience.

\section{Procedures}

For this study, the experimenter has opted for two literature pieces: the classical poem "The Raven" by Edgar Allan Poe, and the autobiographical Slave Narrative: Narrative of the Life of Frederick Douglass, an American Slave. To fulfil this target, the participants had assisted in two tutorials for each literary work, followed by two tutorials of the experiment. To measure any change in the participants' cognitive skills, the inquirer used a language-based technique before the intervention, which capitalised upon a stylistic analysis of the texts carried out in a transmissive learning mood, after those initiative courses, the examinees set for a pre-test (see Appendix A). Afterwards, the same sampling attended extra tutorials in which the classroom was divided into circles composed of ten students; each circle-group works collaboratively through a dialogic model (see Table 1). Following the experiment, the researcher monitored a second test (posttest) to assess the participants' development of outcome after the investigation (see Appendix B).

Table 1. Instructive processes of the treatment

\begin{tabular}{|c|c|c|}
\hline & Methods & Procedures \\
\hline $\begin{array}{l}\text { Before } \\
\text { Treatment }\end{array}$ & $\begin{array}{l}\text { Language- } \\
\text { based } \\
\text { Approach } \\
\text { Teacher- } \\
\text { centred } \\
\text { Model }\end{array}$ & $\begin{array}{l}\text { - The students read a poem or a passage from a narrative in } \\
\text { colouring voices. } \\
\text { - The teacher explains the text by stressing the content (theme, } \\
\text { general ideas, and plot), and the form (literary devices, } \\
\text { language structure, tone and atmosphere). }\end{array}$ \\
\hline $\begin{array}{l}\text { During } \\
\text { Experiment }\end{array}$ & $\begin{array}{l}\text { Heuristic } \\
\text { Approach } \\
\text { A Dialogic } \\
\text { Model }\end{array}$ & $\begin{array}{l}\text { Phase One: (Discursive Talks) } \\
\text { - Defining the problem [question, topic, issue]; } \\
\text { - The learners respond in a collaborative fashion; gathering all } \\
\text { curremt knowledge, reasoning together, then generating } \\
\text { - Resolving an issue by working toward a common vocabulary. } \\
\text { - Creating a common-ground interpretation of meaning }\end{array}$ \\
\hline & & $\begin{array}{l}\text { Phase Two (Argumentation) } \\
\text { - Students discuss new intricate plot in the materials under } \\
\text { study } \\
\text { - Immersion in lively debates that instigate conflicts where } \\
\text { learners express a critical opinion about culural, or rhetorical } \\
\text { issue. } \\
\text { - Constuction of new knowledge generated from different } \\
\text { perspectives (confirming or refuting the proposed solution). }\end{array}$ \\
\hline
\end{tabular}




\section{Interpretation of Results}

Pretest Results

After thorough appraisals of the participants' pretest sheets, the congregation of the final grades calculated through SPSS reveals that students' scores range between a lower-mark zero point five (0.5) obtained by three students and a top mark of (13) recorded by two participants. Involving still, the statistics also show that twenty-two students $(73.3 \%)$ could not reach the average as their marks fluctuate between lower grades 0.5 and 9. Statistics wise, in order to have both a holistic and fragmented picture of the participant's performance in this test, the experimenter has focalised on very substantial parameters, which concern the central tendency of the frequency of distribution, and the measures of variability (see Table 2).

Table 1. Descriptive statistics of the pretest score

\begin{tabular}{|c|c|c|c|c|c|c|c|c|c|c|}
\hline & & Knowled- & Comprehensi- & Applicati- & Argumentati- & Illustra- & Analys- & Evaluati- & Synthe- & $\begin{array}{r}\text { Postte- } \\
\text { st }\end{array}$ \\
\hline & $\mathrm{N}$ & ge & on & on & on & tion & is & on & sis & st \\
\hline $\mathrm{V}$ & 30 & 30 & 30 & 30 & 30 & 30 & 30 & 30 & 30 & 30 \\
\hline Mean & & 1.41 & 1.20 & 9167 & .7167 & .5833 & .5667 & .4833 & .35 & 6.23 \\
\hline Median & & 1.50 & 1.00 & 1.00 & .50 & .50 & .50 & .50 & .00 & 5.75 \\
\hline Std.De & & .573 & 68983 & .70812 & .62537 & .63086 & 63968 & .53310 & .438 & 4.09 \\
\hline Sum & & $42.5 / 75$ & $36 / 75$ & $27 / 75$ & $21.5 / 75$ & $17.5 / 75$ & $17 / 75$ & $14.5 / 75$ & $10.5 / 75$ & $187 / 60$ \\
\hline
\end{tabular}

As displayed in table two, descriptive statistics portray that the general pretest mean is (6.23), and the exact midpoint is 5.75. Besides, the results have also demonstrated through standard deviation that the dispersion between variables is huge (4.09). Regarding the eight skills of critical thinking selected for the testing, the data shows that students had acceptable scores in knowledge (42.5) and comprehension (36), and deficient scores in others levels like synthesis (10.5) and evaluation (14.5).

\section{Posttest Results}

Impressionately, the posttest grades attain the average with a minimum score of 6.5 and a maximum score (15.5). The statistics also showcase that twenty-two students could get the average with scores that oscillate between (10) and (15.5). However, 26.7\% of the participants could not pursue satisfactory results as their marks range from six to nine point five. As far as variability and central tendency measures are concerned, the data depicts that the overall mean of the posttest is 10.98 , and the median score is 10.75. Substantially still, the standard deviation is found out to be satisfactory (2.11), since the value of the dispersion between the variables is not that large (see table 3).

Table 2. Descriptive statistics of the posttest score

\begin{tabular}{|c|c|c|c|c|c|c|c|c|c|c|}
\hline & $\begin{array}{r}\text { Stu } \\
\mathrm{d}\end{array}$ & $\begin{array}{r}\text { Knowled } \\
\text { ge }\end{array}$ & $\begin{array}{r}\text { Comprehensi } \\
\text { on }\end{array}$ & $\begin{array}{r}\text { Applicatio } \\
\mathrm{n}\end{array}$ & $\begin{array}{r}\text { Argumentati } \\
\text { on }\end{array}$ & $\begin{array}{r}\text { Illustr } \\
\text { at }\end{array}$ & $\begin{array}{r}\text { Analysi } \\
\mathrm{S}\end{array}$ & $\begin{array}{r}\text { Evaluatio } \\
n\end{array}$ & $\begin{array}{r}\text { Synthes } \\
\text { is }\end{array}$ & $\begin{array}{r}\text { Postte } \\
\text { st }\end{array}$ \\
\hline $\mathrm{N}$ Val & 30 & 30 & 30 & 30 & 30 & 30 & 30 & 30 & 30 & 30 \\
\hline Mean & & 1.6833 & 1.45 & 1.3667 & 1.3333 & 1.3167 & 1.30 & 1.28 & 1.25 & 10.98 \\
\hline Median & & 1.5000 & 1.50 & 1.50 & 1 & 1.50 & 1.50 & 1.50 & 1.00 & 10.75 \\
\hline Std.De & & .33434 & .56248 & .45359 & 60648 & .46393 & .361 & .503 & .468 & 2.11 \\
\hline Sum & & $50.5 / 75$ & $43.5 / 75$ & $41 / 75$ & $40 / 75$ & $\begin{array}{r}39.5 / 7 \\
5\end{array}$ & $39 / 75$ & $38.5 / 75$ & $37.5 / 75$ & 329.50 \\
\hline
\end{tabular}


Leaning always on the outcome from table three, the particularised view highlights that the total sum germane to each HOTS component is above the average ranging from (50.5) in terms of knowledge and (37.5) for synthesis culminating into a total of 329.50 scores out of six hundred.

\section{Comparison between the Pre/Posttest Scores}

For testing whether the change in the same participants' scores after a course of instruction is statistically significant, the findings of the pretest have been measured up against the posttest through the conduction of Paired-Samples t-Test (SPSS). This Parametric test includes the measurement of the P-value, T-value, and differences in Mean.

Table 3. Paired samples statistics of the participants' pre/posttest scores

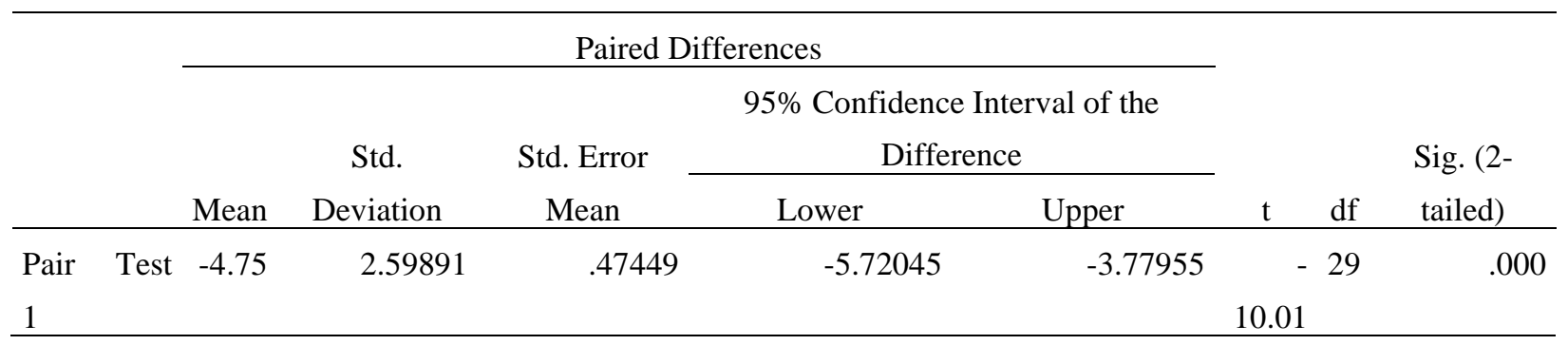

With respect to the shift in the central of tendency (Std. deviation) and the measures of variability (Mean), table four reveals that there is excellent progress in the participants' scores after treatment with a difference of (-4.75) in mean and (2.56) in std. Dev. Crucially enough, the last fundamental point to draw out from these findings is that the difference between the pre and post-test scoring is proved to be statistically significant. One efficient evidence of the effectiveness of the experiment is the $t$-value characterized by a high magnitude far-bigger than $-0 \quad(t=-10.01)$ with a significant degree of freedom in scores $(\mathrm{df}=29)$. Most prominently, the final Paired Samples Test data ensures that the difference between the two mean scores is statistically significant since the $p$-value is smaller than one per cent $(0.001)$, i.e. $(\mathrm{p}=0.000<0.001, \mathrm{t}=-10.01, \mathrm{df}=29)$. Armed by all these statistics, there is now a vital clue upholding the claim that adopting a dialogic argumentative model inside EFL literature classrooms has developed learners HOTSs at the end of the experiment compared to the beginning.

\section{Discussion and Interpretation of the Main Results}

As illumined earlier in this paper, the study targets at calling into question the role of embracing dialogic inquisitive teaching to explore the literary texts and highlights its impact on the 2nd year EFL students' critical thinking skills at Oran2 University. The results of the test gaged through SPSS propel to the substantiation that the implementation of the dialogic teaching model that reconciles between Bakhtin's euphonious dialogues and Socrate's conflicts has enhanced - to a considerable extent- second year EFL learners' HOTSs in an assortment of ways. Fortified by the statistics obtained from the test, 30 participants seem to outperform the pretest results by climbing into positive ranks pursuing thus an enormous leap in mean from 6.23 to 10.98 . Noticeably, the talks ably supervised by the teacher and assisted by team-group share of thoughts is proved to slacken down the cryptic and elusive blind spots of the texts. For instance, the learners in the classroom could negotiate superstitious beliefs and their relation to culture in 
the 'Raven', which the poet personifies as an envisioning of bad omen and upcoming death. Besides this advantage, argumentations could also offer the learners a spacious vent to conjugate their contradictory attitudes and disagreement with many sensitive issues and values which they compared to their own beliefs, cultural stances and experiences. This could say that the final solution is not always that offered by others, but it could pop from one's mind and spirit, then burst into the classroom scene.

In a more detailed fashion, there are many stamps of thriving progress witnessed for each critical thinking skill. Begining by the lower-order five cognitive skills, the findings pinpoint a certain improvement which is not very tempestuous since the learners had already manifested an acceptable level in lower-skills before treatment. For instance, concerning 'knowledge,' the participants have only succeeded to obtain 50.5 points out of 75 points while they had 42.5 points in the pretest. However, for other elements like application and argumentation, a great development in scores is visibly reckoned as the students could outstrip their previous grades striding from (27 and 21.5) to (41 and 40) scores, respectively.

From a brighter corner, enriching the literature classroom through dialogues, debates and autonomy of learning proves a game-changer methodology that promotes learners' HOTSs in a lucid way. As the study illumines, the participants have bared a honed level of strength in many critical thinking skills, not least in synthesis (-27 scores), evaluation (-24 scores) and analysis (22). Transcending beyond numbers to words, these cogent findings entice the researcher literally to embrace the hypothetical assumption avouching that teaching literature through a dynamically dialogic argumentative model has been - to a considerable extent - effective and yielding to the 2nd year EFL students' HOTSs at Oran University (Tlemcen).

The pivotal meaning of this study is to emphasise the fruitful and constructive potential of dialogism to reconfigure the students' cognitive system, by furnishing their brain with new toolkits and privy ideas that help them create a critical and contemplative interpretation of the artworks. It is also a way to toughen the relationships between the learners, and help them foster new learning habits, like the ability to listen to others, accepting other's views forbearingly, and talking out their thoughts intellectually, wittily and respectfully. It is also important to note that the study would help to fill in the gap between literature didactics and applied linguistic theories, by depicting a new model that recycles both of Bakhtin's and Socratic substance of mind. It shows the power of this model as a transparent prism, whose legs often look paradoxical, but in truth, they are ideally equal and complement. Most crucially, the findings of this study suggest that talks alone are not sufficient, and the teachers should monitor their literature classes through the instigation of conflicts and inquiry-based tasks that are ought to stimulate complex and profound engagement with the artefacts affecting prodigiously how readers think, respond, and communicate with the texts. Nevertheless, beyond the idealistic outlooks to the subject, and on the ground of the findings achieved, one would also face scepticism about the possibility of utilizing this complex model with lower-grade learners, wondering how much dialogism may always fit into the picture. Therefore, the study invites the researchers and instructors on a parallel scale to reflect diagnostically about new dialogic techniques that can be conducive to cater to multiple levels of EFL learners' tastes, needs, and learning styles. In a nutshell, the study can confirm that the melting of inquiry and discursive dialogues had offered a great impetus for "bloometizing" $2^{\text {nd }}$ year EFL literature classes, by emboldening the students' thinking habits of 
mind, deepening the learners' understanding of the text, and proffering a new spirit and synergy for intensive readings and analytical strategies.

\section{Conclusion}

Based on the ideas discussed in this paper, one would reassuringly confess that this study could successfully attain the ennobling purpose of this research, which is to sparkle the potential of dialogism inside EFL literature settings and its positive impact on students' cognitive reasoning. As a reminiscence, this modest paper draws favourable notes on the effectiveness of implementing a state-of-the-art dialogic model on the learners' HOTSs. As the study revealed, participants in the majority could develop their cognitive sapience and strategies, especially their highest-order skills (like synthesis, analysis and evaluation) after assisting a vital experiment monitored by the researcher. The findings also unveiled the poor and cons complexities besieging teaching literature through slipshod and transmissive modes of instruction, which limited the learners' understanding of the text and put them inside the shell of passivity and laziness. In the light of this account, we would suggest some core teaching practices like discursive talks, literary circles and Socratic argumentations as a medium to slake the learners' thirst not just to read literature but also to reach into the depth of literary texts. It is also a way to promote commitment and open-mindedness to other's cultures and traditions in the classroom and to supply the learners with the syntax that propels them to cross the hyphen to the kaleidoscopic patterns and properties of the literary world, language and identity metamorphosis engulfed by the wisdom of others and their entrenched mercury of geniuses. All in all, one may say that dialogue foregrounds alternative ways of approaching the rhetorical text(s) irrespective of canonical literary boundaries. However, despite that this paper is suffused effusively with an aura of faith in the ethical and intellectual merits of learning collaboratively, it stays only a signpost towards this attempt. Backlight picture of this subject also shows a lot of thorny perils related to the complexity of summoning up all students to talk, and questions like whether dialogues are always supportive clues inside literature classrooms stay dialectical and unsolved debates to the present time. For this reason and others, the last lines of this research offer an eloquently aspirational appeal to the future researchers -coming with that eagerness in the fieldto surpass the side-effects and the constraints of this study. They are kindly recommended to keep looking for other animating subjects, like interdisciplinary learning and cinematic literature, which may draw a bright vista in the teaching of literature in the future.

Finally, to refine teaching literature in the EFL context, the teachers can apply other instructive tools and methods that may create a convivial atmosphere for nourishing and animating the study of literariness. For instance, in this digital age where people are much stuck to the screen and social media life, teachers can use other active tools, like e-learning and social media resources (e.g., interacting with the students in digital groups in Facebook, Twitter, Instagram, Skype or e-learning platforms). These electronic aids might be pure serendipity for discovery, and a whimsical landscape to critical digital literacy where students can breathe a thinner air of impartiality and amusement, exchange intellectual and emotional 'big thoughts' and also 'silly' and 'genuine' remarks. They can watch films and videos that drive them to appreciate literature as a subtle idiom of life and a fictitious version of reality. They may simply turn into a dynamic and enriching genre of learning so riveting in its very innovative texture and frame. 


\section{About the author}

Dr Amina BOUALI is a senior lecturer at the University of Oran 2 in Algeria. She obtained her $\mathrm{PhD}$ in English Literature from the University of Tlemcen, Algeria. Professionally, her main areas of interest comprise Literature and Cultural Studies, Comparative Literature, and Teaching English as a Foreign Language (TEFL). DOI: http://dx.doi.org/10.24093/awejtls/vol4no2.

\section{References}

Alam, M. M. (2013). Banking Model of Education in Teacher-Centered Class: A Critical Assessment. Research on Humanities and Social Sciences, 3(15), 27-31. Retrieved from https://www.iiste.org/Journals/index.php/RHSS/article/view/7939

Alexander, R. (2020). A Dialogic Teaching Companion. New York, NY: Routledge.

Bakhtin, M. M. (1983). Discourse in the Novel. In M. Holquist (Ed.), \& C. Emerson (Trans.), The Dialogic Imagination: Four Essays (pp. 259-422). Austin: University

Bakhtin, M. (1984). Problems of Dostoevsky's Poetics. Minneapolis: University of Minnesota Press.

Bakhtin, M. (2014). From the prehistory of novelistic discourse. In N. Wood \& D. Lodge (Eds.), Modern Criticism and Theory: A Reader (pp. 235-263). New York: Routledge.

Bloom's Taxonomy of Educational Objectives | The Center for Teaching and Learning | UNC Charlotte. (n.d.). Retrieved July 24, 2020, from https://teaching.uncc.edu/servicesprograms/teaching-guides/course-design/blooms-educational-objectives

Commeyras, M. (1993). Promoting Critical Thinking through Dialogical-Thinking Reading Lessons. The Reading Teacher, 46(6), 486-494.

Delic, H., \& Becirovic, S. (2016). Socratic Method as an Approach to Teaching. European Researcher, 111(10), 511-517. https://doi.org/10.13187/er.2016.111.511

Elder, L., \& Paul, R. (1998). The Role of Socratic Questioning in Thinking, Teaching and Learning. In P. Freire (Ed.), Pedagogy of the Oppressed (pp. 297-302). New York: Continuum.

Fenner, A.-B. (2001). Dialogic Interaction with Literary Texts in the Lower Secondary Classroom. In A.-B. Fenner (Ed.), Cultural Awareness and Language Awareness Based on Dialogic Interaction with Texts in Foreign Language Learning (pp. 13-46). Strasbourg: Council of Europe.

Ferguson, P. M., \& Young, T. A. (1996). Literature Talk: Dialogue Improvisation and Patterned Conversations with Second Language Learners. Language Arts, 73(8), 597-600.

Foster, E. M. (1951, October 7). Sayings of the Week [Quotes].

Freire, P. (2000). Pedagogy of the Oppressed. New York: Continuum.

Freire, P., \& Shor, I. (1987). A Pedagogy for Liberation: Dialogues on Transforming Education. Westport: CT: Bergin \& Garvey.

Hayes, W. (1990). Critical Thinking through Literature: A Dialogue Teaching Model. Critical and Creative Thinking Capstones Collection, 140. Retrieved from https://scholarworks.umb.edu/cct_capstone/140

Koschmann, T. (2015). Toward a Dialogic Theory of Learning: Bakhtin's Contribution to Understanding Learning in Settings of Collaboration. 1-12. Palo Alto, California: Mahwah, NJ: Lawrence Erlbaum Associates.

Kozulin, A. (1996). A literary model for psychology. In D. Hicks (Ed.), Discourse, Learning, and Schooling (pp. 145-164). Cambridge: Cambridge University Press. https://doi.org/10.1017/CBO9780511720390.005 
Langer, J. A. (1995). Envisioning Literature: Literary Understanding and Literature Instruction. New York: Teachers College Press.

Larson, L. C. (2009). Reader Response Meets New Literacies: Empowering Readers in Online Learning Communities. The Reading Teacher, 62(8), 638-648.

Littleton, K., \& Howe, C. (Eds.). (2010). Educational Dialogues: Understanding and Promoting Productive interaction. Routledge.

Littleton, K., \& Mercer, N. (2013). Interthinking: Putting talk to work. Abingdon, Oxon: Routledge.

Lyle, S. (2008). Dialogic Teaching: Discussing Theoretical Contexts and Reviewing Evidence from Classroom Practice. Language and Education, 22(3), 222-240. https://doi.org/10.1080/09500780802152499

Morgan, C., \& Cain, A. (2000). Foreign Language and Culture Learning from a Dialogic Perspective. Clevedon England: Multilingual Matters.

Murphy, P. K., Wilkinson, I. A. G., Soter, A. O., Hennessey, M. N., \& Alexander, J. F. (2009). Examining the Effects of Classroom Discussion on Students' Comprehension of Text: A Meta-Analysis. Journal of Educational Psychology, 101(3), 740-764. https://doi.org/10.1037/a0015576

Parker, W. C. (2010). Listening to Strangers: Classroom Discussion in Democratic Education. Teachers College Record, 112(11), 2815-2832.

Paul, R., \& Elder, L. (2003). The Miniature Guide to Critical Thinking Concepts and Tools. Dillon Beach, Calif: Foundation for Critical Thinking.

Renshaw, P. D. (2004). Dialogic teaching, learning and instruction: Theoretical roots and analytical frameworks. In J. van den Linden \& P. D. Renshaw (Eds.), Dialogic Learning: Shifting Perspectives to Learning, Instruction, and Teaching (pp. 1-15). Dordrecht; New York: Springer.

Reznitskaya, A. (2012). Dialogic Teaching: Rethinking Language Use during Literature Discussions. Reading Teacher, 65(7), 446-456. https://doi.org/10.1002/TRTR.01066

Reznitskaya, A., \& Gregory, M. (2013). Student Thought and Classroom Language: Examining the Mechanisms of Change in Dialogic Teaching. Educational Psychologist, 48(2), 114133. https://doi.org/10.1080/00461520.2013.775898

Reznitskaya, A., Kuo, L.-J., Clark, A.-M., Miller, B., Jadallah, M., Anderson, R. C., \& NguyenJahiel, K. (2009). Collaborative reasoning: A dialogic approach to group discussions. Cambridge Journal of Education, 39(1), 29-48. https://doi.org/10.1080/03057640802701952

Schultz, J. M. (2001). The Gordian Knot: Language, Literature, and Critical Thinking. In V. M. Scott, H. Tucker, \& S. S. Magnan (Eds.), SLA and the Literature Classroom: Fostering Dialogues, 2001 AAUSC Volume (pp. 3-31). Boston: Heinle.

Seymour, M., Thanos, T., Newell, G. E., \& Bloome, D. (2020). Teaching Literature Using Dialogic Literary Argumentation. In Routledge, Taylor \& Francis Group. Routledge: Taylor \& Francis Group.

Skidmore, D., \& Murakami, K. (2016). Dialogic Pedagogy: An Introduction. In D. Skidmore \& K. Murakami (Eds.), Dialogic Pedagogy: The Importance of Dialogue in Teaching and Learning (pp. 1-16). Bristol; Buffalo: Multilingual Matters.

Strickland, D. S., Dillon, R. M., Funkhouser, L., Glick, M., \& Rogers, C. (1989). Research Currents: Classroom Dialogue During Literature Response Groups. Language Arts, 66(2), 192-200. 
Weigand, E. (2004). Emotion in Dialogic Interaction: Advances in the Complex. Amsterdam; Philadelphia: John Benjamins Publishing Co.

Wells, G. (2009). The Meaning Makers: Learning to Talk and Talking to Learn. Bristol, UK; Buffalo, NY: Multilingual Matters.

Wolfe, D., \& Alexander, R. (2008). Argumentation and dialogic teaching: Alternative pedagogies for a changing world. London: Futurelab.

Woodruff, A., \& Griffin, R. (2017). Reader response in secondary settings: Increasing comprehension through meaningful interactions with literary texts. Texas Journal of Literacy Education, 5(2), 108-116.

\section{Appendix A. Pretest}

\section{L2 (Group A)}

2018/2019

Time alloted $(1 \mathrm{~h} 30)$

\section{Pretest in Literary Studies}

Discuss one of the following topics:

1. What is the effect of the ecophobia implied in Poe's Gothic poetry 'The Raven' on the way people deal with their social, political, and cultural environment in the 'real' world?

2. Can we think of The Narrative of the Life of Frederick Douglass as an implicit way to seek out emancipation through literacy?

\section{Appendix B. Posttest}

L2 (Group A)

2018/2019

Time alloted (1h30)

\section{Posttest in Literary Studies}

Answer one of the following questions:

1. It is said that Gothic poetry has the tendency to deal with complex matters, "the narrator knows full well how the creature will respond, but he continues anyway. To him, the raven's stubborn consistency offers an opportunity to probe the dark interior of his own mind, his own fears and doubts." (Tom J. Hillard, "Deep Into That Darkness Peering," p. 694)

- Discuss

2. Discuss aspects of double-counsciousness embedded in The Narrative of the Life of Frederick Douglass, and their role in shaping the Afro-american black identity and history of the author. 